\title{
واجب الوفاء للمرحوم عبد الوهاب المسيري
}

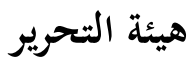

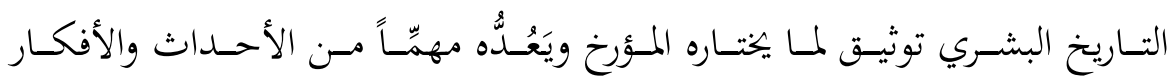

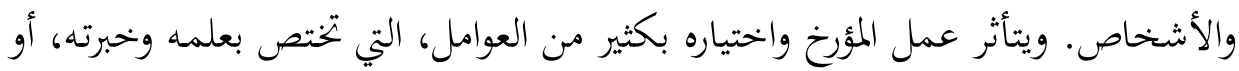

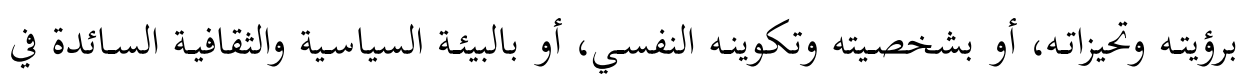

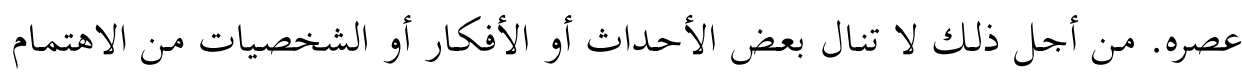

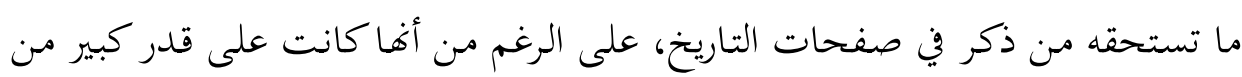

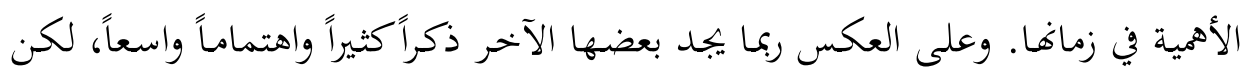
الأجيال التالية لا تلقي له بالاً.

وقد شهد التاريخ الإسلامي في مراحله المتتابعة شخصيات في ميادين العلم والأدب

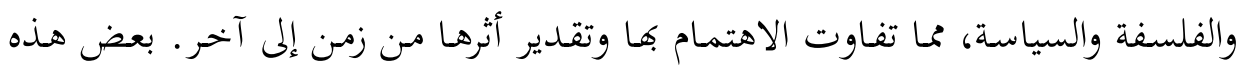

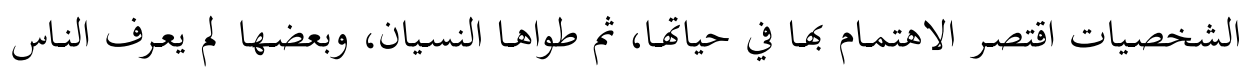

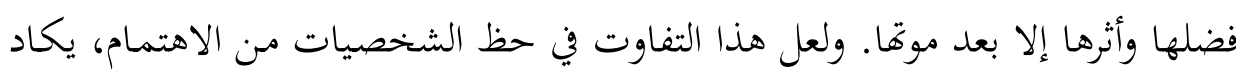
يكون ظاهرة عامة في حياة الشعوب في التاريخ القدي والحديث.

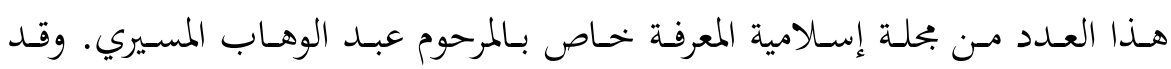

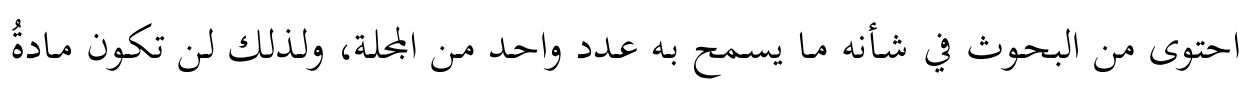

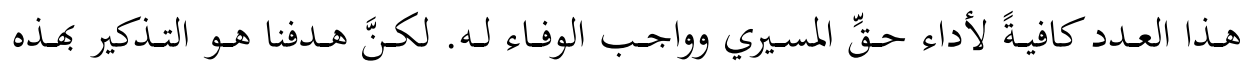

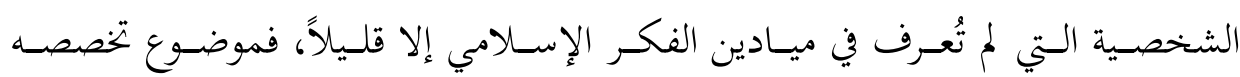

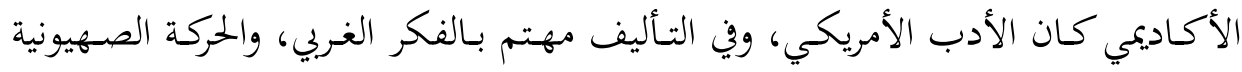

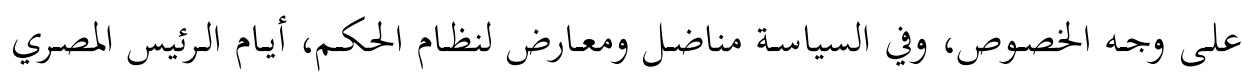

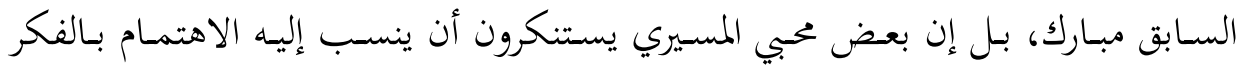


الإسلامي. ولذلك فإن الواجب الأكاديمي الإنساني المتصل بالتأريخ للمسيري، والواجب الأدبي والخلقي المتعلقق بأمانـة العلـم والمتصـل بالجحوانـب الأخـرى مـن حياتـه واهتماماتـه، تفرض أن يتولى الأوفياء له، توثيق صلته بالفكر الإسلامي المعاصر وإبحازاته فيه. انضم المسيري إلى البملس العلمي للمعهد العالمي للفكر الإسلامي في مكتب المعهد في القـاهرة الذي ترأسه الشيخ محمد الغزالي حتى تاريخ وفاة الأخير، يرحم الله الاثنين.

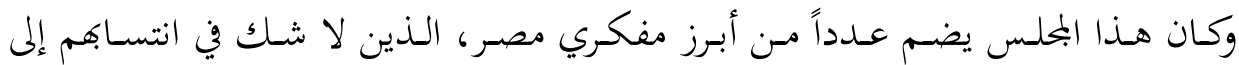
الفكـر الإسـلامي. كمـا أصسبح بعـد ذلك عضـواً في المحلس العلمي العـالمي للمعهـد، وتواصلت صـلته بالمعهد وبرابحهـ ونشـاطاته حتى تاريخ وفاتـه. ولكن ذلك لم يمنعـه مـن الاحتفـاظ بصـلات جيـدة مع كثير من الشخصيات الوطنيـة والقومية، في دوائر الفكر والثقافة والسياسة.

لقــــكان مـن أهــم مـا شـارك بـه المسـيري في نشـاطات المعهـــ هـو إعمـال الرؤيـة التحليلية النقدية للفكر الغربي، والكشف عن النماذج المعرفية الكامنـة في هـا الفكر، وتحيزاته في بحالات العلوم الطبيعية واللغوية والاجتماعية والإنسانية. وقد أوكل المعهد إلى المسـيري مهمـة الإدارة العلميـة للمؤتمر الأول للتحيز عـام بو 99 ام، الذذي نظمـه المعهـد بالتعاون مع نقابة المهندسين في مصر، كما أوكل إليه المعهد كذلك مهمة الإدارة العلمية للمؤتمر الثاني للتحيز عام V • . ب ام. وكان للمسيري إسهام مميز في الجلسات المتوالية لفريق من العلماء الذين تواصلت لقاءاتم مدة سنتين لإبحاز كتاب المنهجية الإسلامية. والقـارئ لكتابـات المسـيري يلحظ الهمَّ الفكري الذي يتجاوز ظواهر الأحـداث إلى عمق التحليل، ومقـادير الكم إلى نوعيـة الكيف، وسطحية الوصف إلى عمق التفسير،

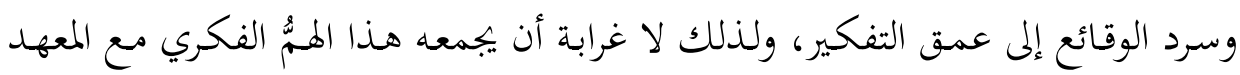
العـالمي للفكر الإسـلامي، ولا سيما في البحـث عـن الرؤيـة الكونيـة التوحيديـة في الفكر الإسلامي، والكشف عن الرؤية الحلولية وتماذجها المادية غير الإنسانية في الفكر الغربي، 


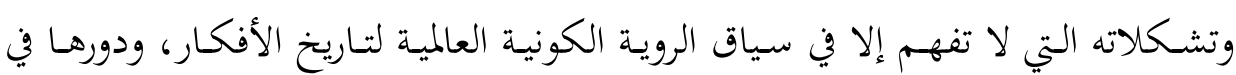

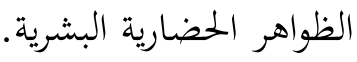

في تموز \99 199 استضاف المعهد العالمي للفكر الإسلامي-مكتب الأردن المرحوم

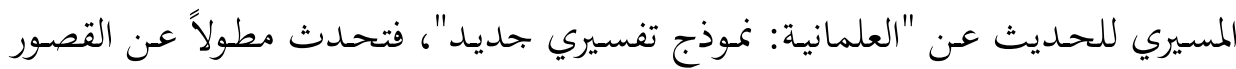

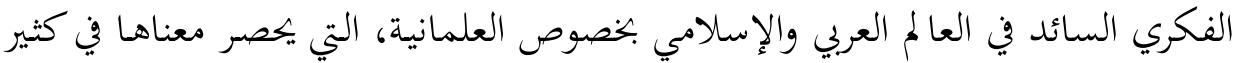

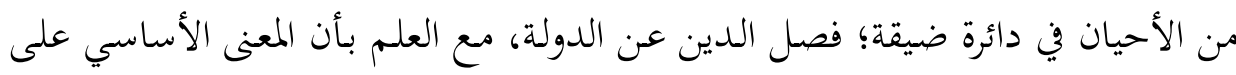

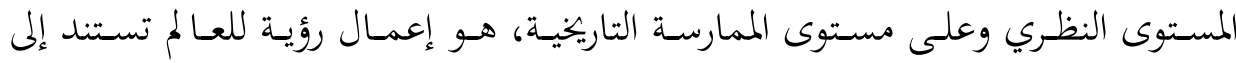

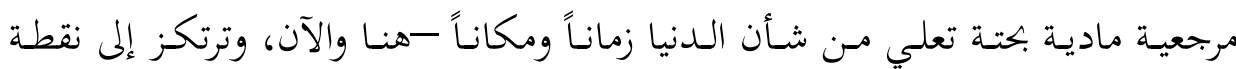

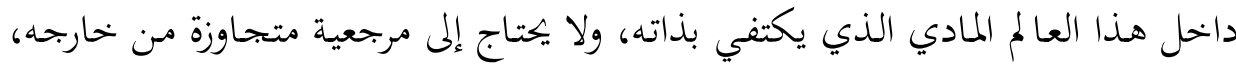

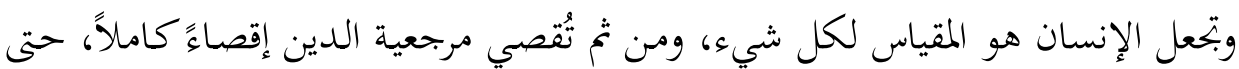

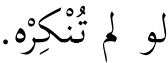

ومع ذلك فإنَّ المسيري ميّز بين نوعين من العلمانية، سمّى الأول منهما "العلمانية

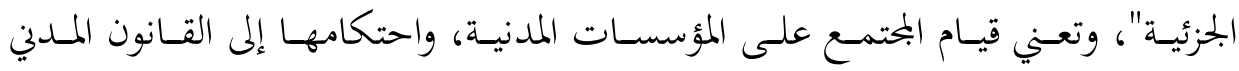
الوضعي بما في ذلك المؤسسة الدينية، التي تمارس عملها ضمن قواعد التهد النظام الديمقراطي

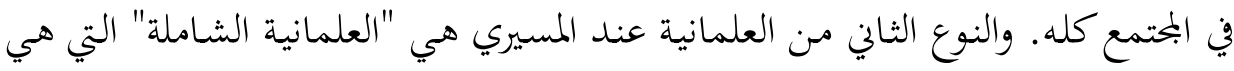

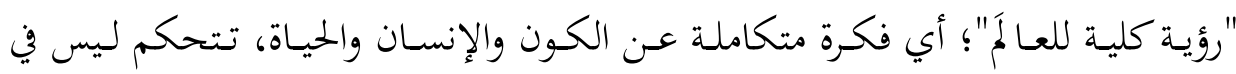

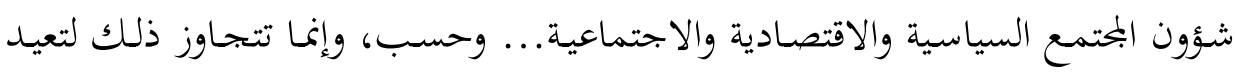

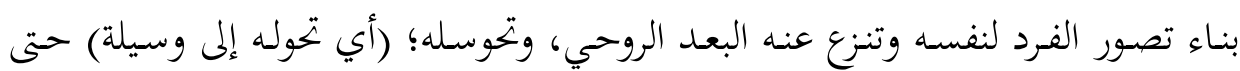

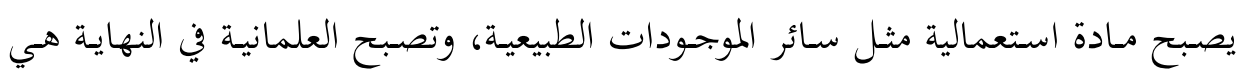

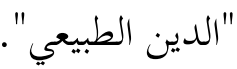

وفي عـام 991 ام نظمبم مكتـب المعهـد في الأردن حلقـة دراسية بعنوان "نحو نظام

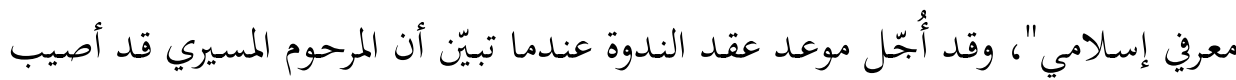

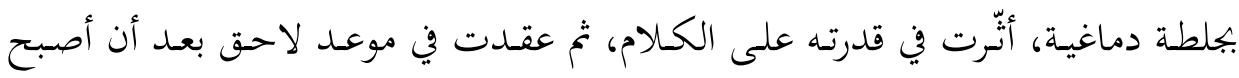


المسيري قادراً على الحضور • وقد أشفق المشاركون في الندوة على المسيرى لما لاحظوه من صعوبة في الكلام. وكان حرصنا على مشاركة المسيري نابعاً من رغبتنا في الاستماع إليه أولاً حسول مفهوم النظام المعرفي، قبل الدخول في مناقشات أخرى تتعلق بمصادر النظام المعريي وأدواته وتمثلاته في العلوم، وأدبياته في التاريخ الإسلامي، وموقعه في الصراع الفكري والإيديولوجي والسياسي المعاصر، وغير ذلك من الموضوعات والقضايا المعرفية.

وقد أعدّ المسيري مداخلة مكتوبة، 'أوضح فيها رؤيته للدلالة التي يفضِّل أن تعطى للموضوع الذي يُعَدُّ موضوعاً معرفياً، في مقابل ما يعد سياسياً أو اقتصادياً أو تاريخياً.

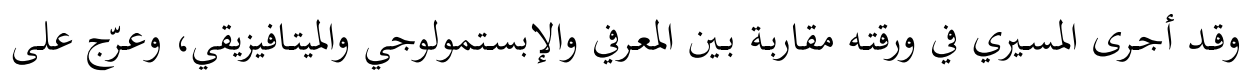
الدلالات التي تعطيها مرجعيـات الفلسفة وتـاريخ العلوم والأفكار، والمعـاجم الإبحليزيـة والفرنسية، واختـار أن يهـد معنى المعريف مـن دلالات المعجـم العربي، الذي يهـدد دلالة المعرفة بأها: "إدراك الشيء على حقيقته... وحيث إن ذلك يعني ضرورة التجريد للوصول إلى المعنى الكلي أو إلى النموذج الكامن، فإن عبارة مثل "المستوى المعريف" تعني المستوى الذي يتم فيه إدراك الحقيقة الكلية والنهائية الكامنة وراء ظاهرة أو نص مـا. ويتم ذلك

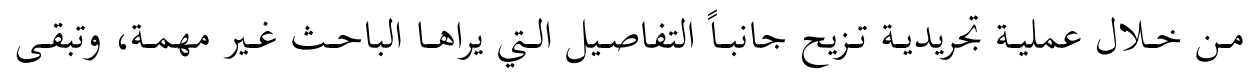
السـمات الأصلية الجوهريـة للشيء، التي تشكِّلُ في واقع الأمر إجابـةً النص أو الظـاهرة على الأسئلة الكلية والنهائية... وهي تدور حول الإنسان والإله والطبيعة." وبـيّن المســيري أنَّ أيَّ تحليـل سياسـي أو اقتصـادي يهـاول الإجابـة عـن الأســلة

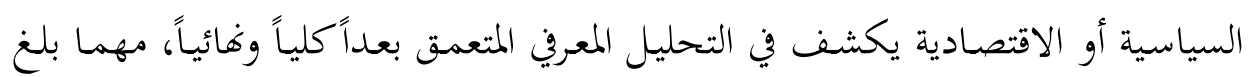
مـن الحيادية والتجريدية والسطحية. وضـرب المسيري أمثلة متعـددة على مـا يُعـدُّ قضايا

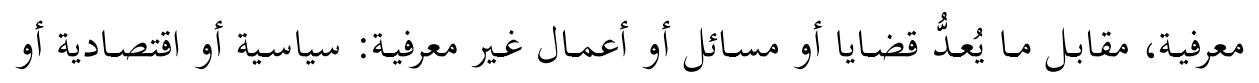
خيرية، أو أخلاقية، إلخ.

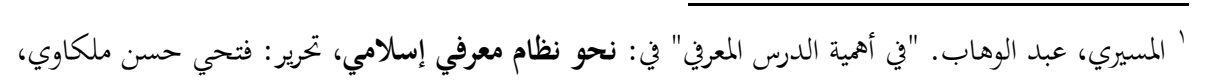

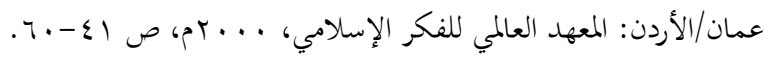


وأوضح المسيري أهمية الدرس المعرفي بالتأكيد أنّ كل إنسان يستخدم نماذج معرفية لمسرية

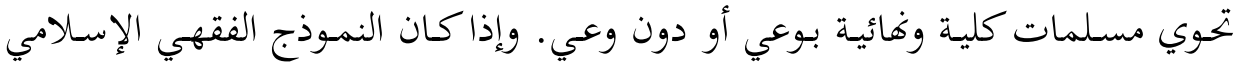

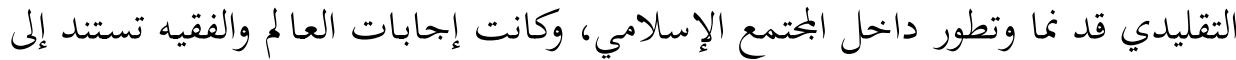

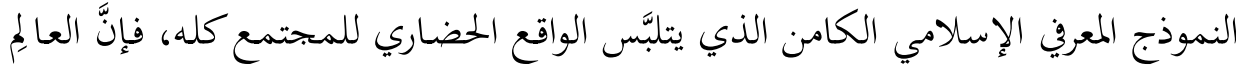

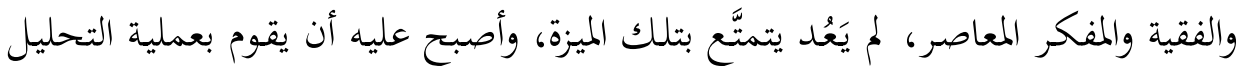

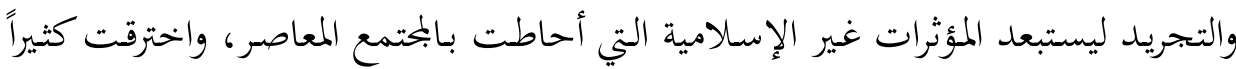
من مفاهيمنا، وأنماط حياتنا، ومشاعرنا. وقد كانت مداخلة المسيري في الحلقة الدراسية المذكورة نموذجاً من التحليل المعريف

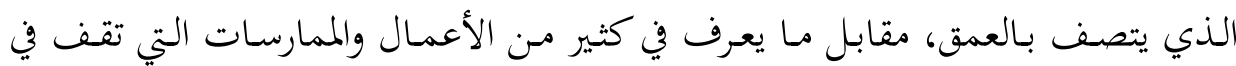

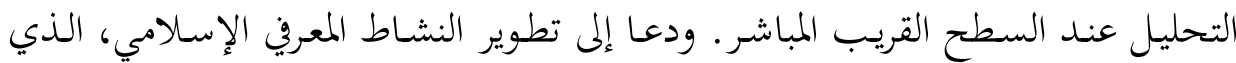
يمكِّن المفكر المسلم من الوصول إلى مقولات تحليلية ذات قدرة تفسيرية عالية.

وثمة مناسبة ثالثة استضاف فيها مكتب المعهده في الأردن المرحوم المسيري، تلك هي

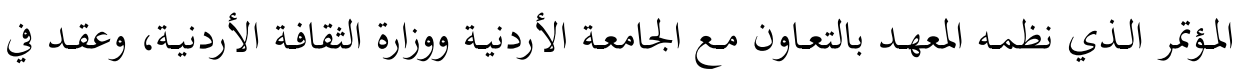

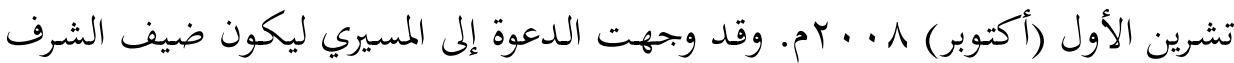

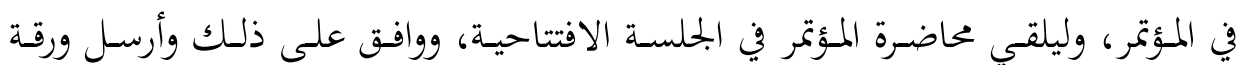
مطولة بعنوان "من ضيق المادية إلى رحابة الإنسانية والإيمان"، وقد وافاه الأجل في يوليو

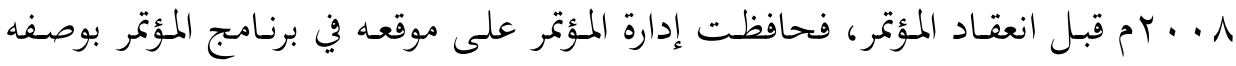

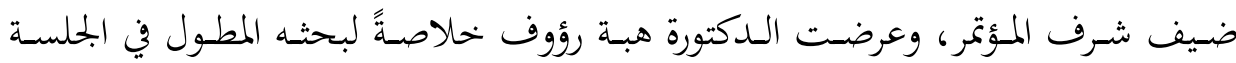
الافتتاحية للمؤتمر.

كان موضوع البحث هو الإنسان في الفكر المعاصر، وقد ميَّز المسيري بين رؤيتين لإإنسان تذهب الأولى منهما إلى أنّ الإنسان كائن مـادي محض، والثانية إلى أنه كائن مركب من عناصر مادية وعناصر غير مادية. وميّز كذلك بين الإنسان والطبيعة على الطى 
أساس المرجعية التي يستند إليها التمييز. وهو يلاحظ أنّ معظم النصوص الفلسفية الغربية الحديثة تستند في رؤيتها للإنسان إلى مرجعية طبيعية مادية؛ إذ تكون الطبيعة فيها نظاماً مكتفياً بذاته، وتوجد مقومات وجوده وحركته داخله، وهو بذلك "نظام واحدي مغلق". والإنسـان في هـذا النظام خاضع لقـوانين الطبيعـة وحتمياتها، وبــلاً مـن ثنائيـة الإنسـاني والطبيعي، تظهر "الواحدية الطبيعية/المادية."

لكـن المسـيري وهـو يتجـاوز هـذه الرؤيـة الاختزاليـة للإنسـان ويُعهـل رؤيتَه الإيمانيـة،

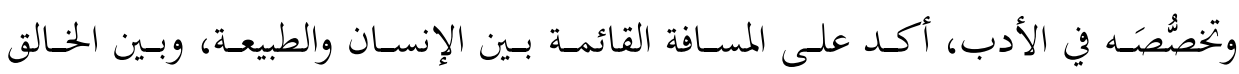
والمخلوق، وبين الروح والجسـد، وغير ذلك مـن الثنائيات الأساسية في الكون. ومهع أن الإن النمـوذج الفعـال في الحضـارة الغربيـة الحلديثـة هـو ذلك النمـوذج الواحـدي المـادي، وهـو النموذج المسيطر على النظم السياسية والاقتصادية الذي يعلن الجميع ولاءهـم له، فإن كثيراً من الناس في الغرب يسلكون طريقة تتنافى مع هذا النموذج؛ فتجد ثنائيات الخير والشر، والمقدس والمدنس والمطلق والنسبي، حاضرةً بقوة الإدراك الفطري لثنائية الإنسان والطبيعـة، وتؤكــــ العلاقـات الإنسـانية الفكريـة نفسـها بطريقـة تتحـدى النمـوذج الفعـال المسيطر.

ويختم المسيري ملاحظته بروح متفائلة كعادته، مؤكداً: "أن العنصر الرباني في الإنسان

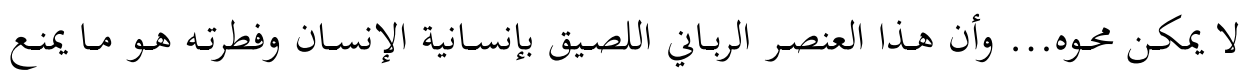
النموذج الطبيعي/ المادي من التحقق الكامل، ومن الوصول إلى اللحظة النماذجية ونقطة الصفر الماديـة، إلا في لحظات نـادرة. وإذا كانت اللحظة النماذجية العلمانية هي للظة

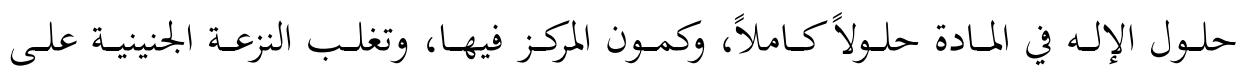
الإنسان، فإنَّ الإله الخفيَّ هو تعبير عن أنَّ الإله حي لا يموت، وأن ما حدث ليس موتاً للإله نتيجة حلوله في المادة، وتوحدّه بها، واستيعابه فيها (فهو متجاوز للطبيعة والمادة)،

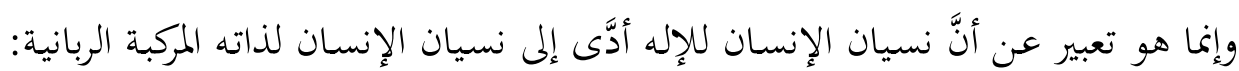




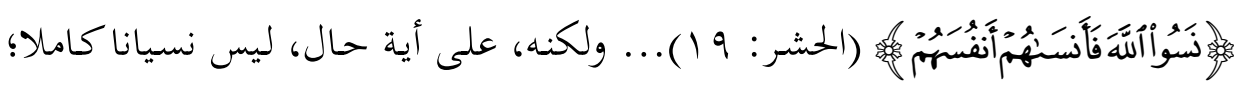

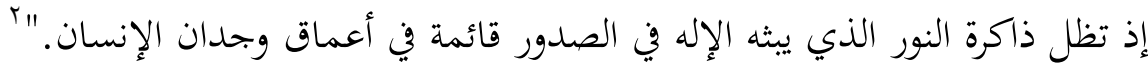

لم يكن هـدفنا من هـذه الإشـارات الثلاث رصدـ جميع المناسبات التي ظهر فيها

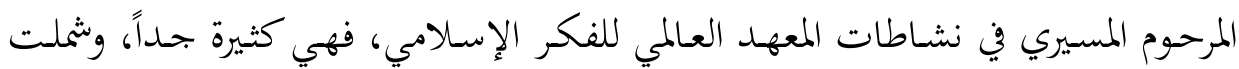
نشاطات المعهد في كثير من الأقطار في أمريكا وأوربا وإفريقيا وآسيا. وإذ نكتفي بها فما ذكرنا

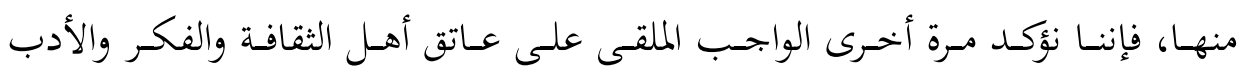

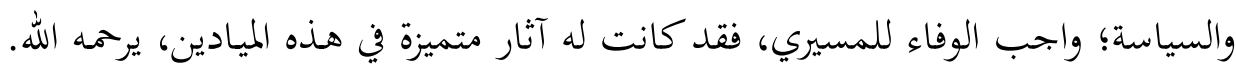

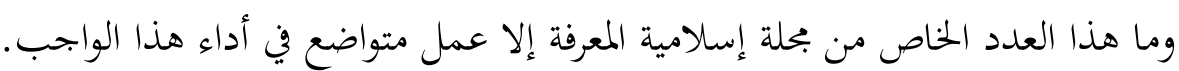
إن بحوث هذا العدد لا تغطي جوانب المسيري الفكرية والمعرفية كلها، ولكن حسبها

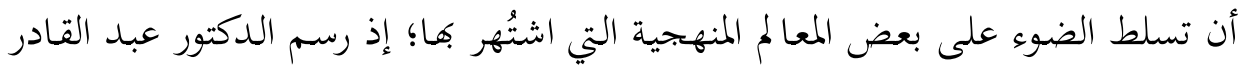

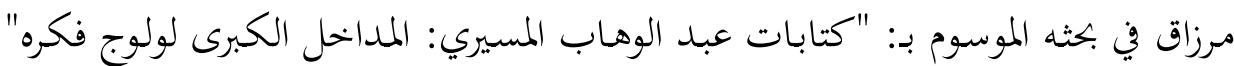

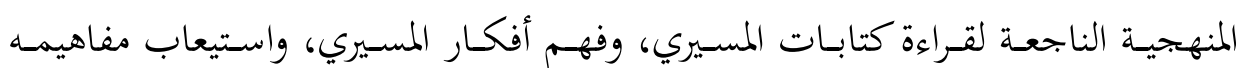
ومصطلحاته في سياقاتا المختلفة.

وثمة قراءة معرفية لمنهج المسيري، المستند إلى مرجعية معرفية توحيدية، بلورت نظرة

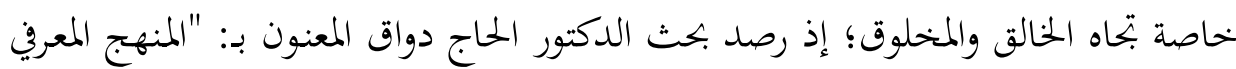

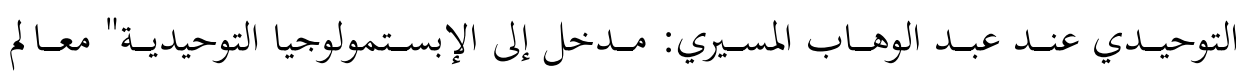

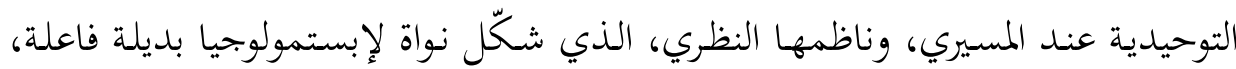

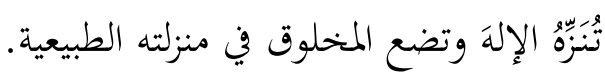

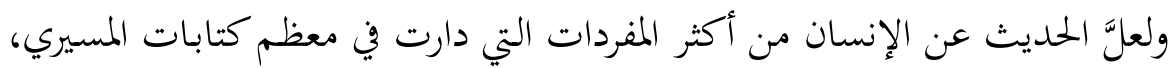

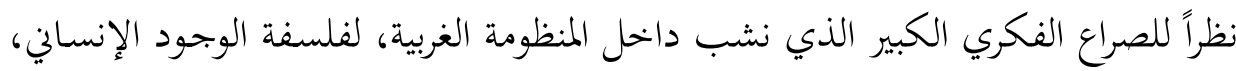

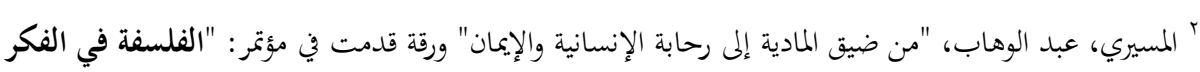

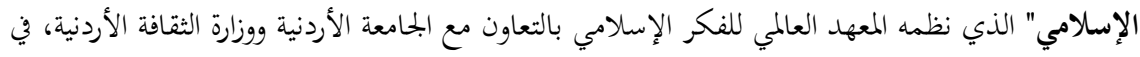

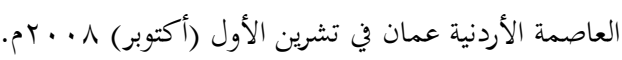


وماهيته، وحقيقته، وعلاقته بالخالق، ومركزيته في الكون. وقد حاول الأستاذ رحماني ميلود في بكثه: "الإنسان في المرجعية المتجاوزة عند عبد الوهاب المسيري" أن يجلّيَ قراءة المسيري النقدية لموضوع الإنسان في الرؤية المادية الغربية، مـن خهلال تفكيكه للمنظومة الفكرية الغربية، ويكشفَ في الوقت نفسه عن البناء المعرفي الإسلامي الذي انطلق منه المسيري في بلورة التصور الإسلامي للإنسان في هذا الكون. وحاولت دراسة الدكتوره رزان محمود إبراهيم الموسومة ب: "رحلة عبد الوهاب المسيري الفكرية: دراسة في المقاصد والمنهج" استحضار الآليات التي اعتمدها المسيري في تحليلاته للنماذج المعرفية؛ إذ كشفت عن المنطلقات التأسيسية، التي انطلق منها المسيري في فهمه للوقائع التاريخية والأدبية والسياسية...، ومدى بحاح منهج دراسة الصور البحازية في تحليل الظواهر، لا سيما تلك المتعلقة بالعقل الصهيوني، والحمداثة، وما بعد الحداثة. 